\title{
Review of the Corporate Governance and Its Effects on the Disruptive Technology Environment
}

\author{
HOSSAM HADDAD ${ }^{* 1}$, DINA ALKHODARI ${ }^{2}$, REEM AL-ARAJ $^{3}$, NEMER ABURUMMAN $^{4}$, \\ JIHAD FRAIJ $^{5}$
}

\author{
${ }^{1}$ Financial and Accounting Sciences Department, Middle East University, Amman, JORDAN \\ ${ }^{2}$ Business Administration Department, Middle East University, Amman, JORDAN \\ ${ }^{3}$ Financial and Accounting Sciences Department, Middle East University, Amman, JORDAN \\ ${ }^{4}$ Doctoral School of Management and Business, University of Debrecen, Debrecen, HUNGARY \\ ${ }^{4}$ Doctoral School of Management and Business, University of Debrecen, Debrecen, HUNGARY
}

\begin{abstract}
This paper investigates how the invention governance could sustain a way which serves as a path in a disruptive environment. The importance of this study is to incubate a structure to assess and revise the latest disruptive technology and innovations (DTIs). From organizational point of view, this paper reviews the generic features of disruptive technology and innovations, and its influences for the fundamental and layout of corporate governance and accounting techniques. In addition, the paper clarifies and determinates the characteristics of emerging and disruptive technology and innovations-related form patterns which constitute needed permutations to corporate governance and the mechanisms of accounting. A systematic literature review was adopted considering the defined previous studies steps. The nature of the literature review breaks the barriers for readers to understand and analyse the effects of corporate governance on disrupted technology. The paper rounds off by suggesting sundry studies on design and other innovation and sustainable systems of governance, Moreover, depending on theoretical and methodological point of view and encouraging the further research, which adopt this kind of topics.
\end{abstract}

Keywords: - Corporate Governance, Disruptive technology, innovation, Common Technology, Audit, Financial Reporting.

Received: May 2, 2021. Revised: September 10, 2021. Accepted: September 18, 2021. Published: September 24, 2021.

\section{Introduction}

As a consequence of disruptive technologies and developments, the technological revolution has changed our way of thinking about business models and corporate governance in today's business environment (DTI). Unprecedented developments have occurred since advanced technologies such as the Internet of Things, artificial intelligence, and block chains entered the industry, primarily disrupting and affecting the conventional chains of the way goods and services are created and consumed. [5; 30]. People have become completely reliant on processing huge quantities of data in complicated and high-speed technologies by using integrated multi-platforms and networked structures that allow for innovations such as bitcoin marketplaces and common economies. [37] . [87] This has been dubbed the industry 4.0 revolution, which is a foresight that will result in changes to whole manufacturing processes, management, and corporate governance. [34] Shed light on the fact that disruptive technology use technology to alter the fundamentals of competition by changing performance measures alongside competing businesses. As a result, for accountants, finance, administration, management, and other governance experts, these changes put a lot of strain on information systems and governance, which necessitates more flexible methods as well as sophisticated and future systems. [50]. Furthermore, businesses must be aware of the risk boundaries and their consequences as a result of disruptive technologies and innovations, as well as be prepared to respond as successful or unsuccessful. However, few overviews of the layout of appropriate governance systems for entities linked to disruptive technologies and innovations were given to the literatures. Indeed, it is difficult to anticipate the evolution of technical breakthroughs due to nature, which is considered to clash with more traditional tendencies with top-down mainly hierarchical control and less self-organization. [95] . It seems that literature efforts are focused on developing disruptive technology management, as well as the 
design and efficacy of corporate governance and accounting information system methods. For example, there are about 1078 disruption research publications. [52] Determine ten studies related to accounting and finance.

Furthermore, the researchers have noted that there is a significant distinction between articles addressing revolutionary and disruptive innovations and studies addressing organizational capabilities for business-model operations. On the other hand, many perspectives on disruptive technology and innovation governance systems have been presented. These systems are critical for efficient and dynamic policymaking by regulators, governments, and decision-makers.

The primary goal of this article is to identify and discuss the new challenges that emerge as a result of disruptive technologies and their societal consequences for organizational governance. The overview's goals are as follows:

This article has shed light on the general characteristics of disruptive technologies and innovations, as well as their consequences for the design and principles of corporate governance and accounting methods, at the organizational level.

To identify the familiar features of emerging disruptive technologies and innovations, as well as associated structural patterns that actualize the need for and changes to accounting governance and procedures.

Several topics of design innovation and sustainable governance systems have been proposed for future research, drawing on specializations in theoretical and methodological aspects.

The debate was based on the literature on disruptive technology and innovations, which is supported by common structures that include the implicit characteristics of such technologies and innovations, as well as elements of corporate governance, economic systems, and expected outcomes, as shown in Figure 1. The researchers initiated the work by discussing the concept and characteristics of disruptive technology and innovations, as well as various explanations of the main types of disruptive technology and innovations, such as Big data, Blockchain, cryptocurrency, share the economic with crowdfunding, and outsourcing, as well as their impact on governance and accountability, as well as the decision-making process. We also highlight a number of developing or other disruptive technology and innovation patterns (rapid, cooperative, decentralized, and shared institutional forms) that suggest diversity model and ability aspects. This article will discuss the effects of redesigning corporate governance and accounting processes in order to suit shifting needs. In addition, several papers discussed $[60 ; 63 ; 67]$ to add a new sight about what does work and what does not through disruptive technology and innovations and the concerning demands that are imposed by the dynamic environments and more changeful.

\section{Literature Review}

\subsection{Innovations and Disruptive Technology}

This part will assess the disruptive technology and innovations characteristics, supported by technological disruptive capabilities.

\subsubsection{Characteristics of Disruptive Technology and Innovations}

[73] mentioned that according to the previous studies, the technology is thematic, it has an extrinsic power, and it will have a significant impact on organizational features such as structure. Later scholars concentrated on the human element of technology, seeing it as the result of strategic decision-making and social activity. This study contends that either viewpoint is inadequate and offers a rethinking of technology that takes both views into consideration. This remark shows an early misguided conception of technology as being technologically neutral. The socio-technical viewpoint considers the social to be essential and investigates how the technology and the social interact in a bi-directional manner. However, this field of study focuses on social determinism. This viewpoint is particularly problematic since it gives human actors far too much authority while giving tools far too little. Since then, a third wave has emerged with a socio-material lens, proposing a post-actor-network theory vision of the world in which neither the social nor the technological can be regarded as main influences, but both are intertwined, imbricated, or assembled. For instance, activity theorists often emphasize that, by definition, the object of the activity is emergent, fractured, and contradictory due to its communal origin. This idea implies that we must address the function of technology in a variety of ways [70].

Hence, we have to the understanding that we have to pathway the function of technology in the different ways. [58] stated that the disruptive technologies may be mixed group of existing technology or modern one with its applications to disruptive parts or latest marketing challenges. (for example, the structures and transactions) may make the main technology product paradigm move or 
originate new one. Disruptive technologies have been defined as the technology which damages the fundamental path of performance refinement or restructure of the definition of the meaning of performance [27]. Blockchain technology, artificial intelligence, digital technologies, shared economy models, and other disruptive technologies are examples. In disruptive settings, innovations are often unexpected, ideas are radical, results are unclear and ill-defined, and justifying investments in them is difficult since markets are either underdeveloped or non-existent. [43] .

Prior studies have focused on disruptive technology and innovations $[28 ; 30 ; 29]$ and assume the disruptive technology has occurred when the administrators were keen and caring of the customer retention. The studies showed that the performance path of prospective technology to single out each one's need and pay attention to it. $[30 ; 26]$ have debated according to [78] incidents of disruptions that have distressing influences occupants. Moreover, the main conclusion stated that there are two kinds of technological developments. Firstly, is the sustaining technology, which has been adopted by the high-performance companies of the industry, which develops the standard of the product performance regardless of the difficulties from incremental to reach the radical. Secondly is a disruptive technology we can say caused the failure of the pioneer companies in the same industry. However, it disrupts the innovations or redefined the path of the performance. The flourishing companies hazard failure if they have not realized the difference between sustained and disruptive technologies in addition if they missed and failed investing in emerging disruptive technologies [57].
[58] pointed out that the decreasing of the potential reasons referred to (a) the disruptive products which are more manageable, cheap, lower as promised, low-profit margin(b) disruptive innovations typical are marketed in emerging or small markets;(c) Customers do not look for the leading companies that earn more profit, in reality originally cannot use products related to disruptive technologies.

Popular technology background characteristics and disruptive developments include fast-changing climate, emerging technologies, and unpredictable competitive markets. [31;76] noted out that there is a relationship between corporate governance and disruptive technology and innovations with several suggestions for implementing various disciplines and theoretical frameworks to develop the governance systems that facilitate the decision making in the environments that have described as unpredictable, complicated, and dynamic. The decision-making framework was designed to be more consistent and versatile, which is essentially the corporate governance standards such as accountability, transparency, and disclosure and combined with the systems of the governance systems processes. On the other hand, cooperative systems, transactions, alliances, shared networks are enablers which relayed on the integration of technologies as a part of disruptive technology and its innovations $[3 ; 81]$.In this respect, the role in decision-making is a more important delegation in the eco-system in disruptive technologies and innovation. Although some developments that result in technology enabling improvements to governance structures, risks associated with the deterioration of oversight and quality of governance are also probable. 


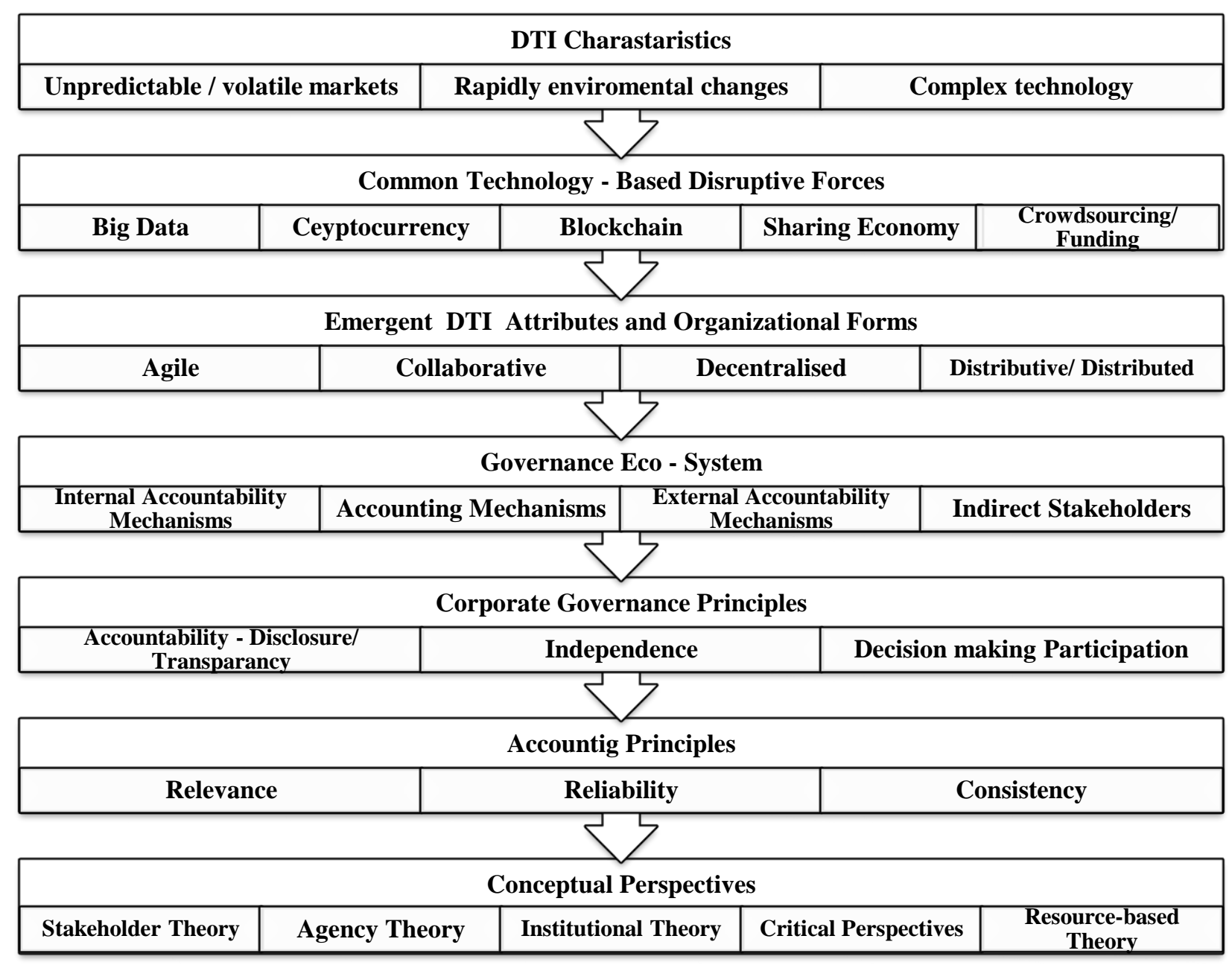

Fig.1: The main structure of disruptive technology and innovation governance

Source: Created by authors

\subsection{Common Technology}

In this section, we'll go through the five most frequent technological disruptions that have radically altered company models in unexpected ways. As seen in Table 1, the top five disruptive technologies and developments are Big Data, bitcoin, the blockchain and crowdsourcing. Disruptive forces are divided into two categories:

(a) Technology advancements connected with digitalization data and data reform opportunities

(b) Disruptive technologies that affect decisionmaking or financial processes, such as Big Data and cryptocurrencies.

Technology such as blockchain, the sharing economy, and crowdsourcing forms are used to manage and report on innovations that change the way corporate operations are carried out.

\subsubsection{Big Data}

Whatever the long definition, [16] have introduced, but it is a full explanation of the big data as follows:

A cultural technical and academic phenomenon focused on the interaction of:

Technology: optimizing computational power and algorithmic precision for storing, analyzing, connecting, and comparing large information groups.

Analysis: relying on many data groups to assess claims trends such as cultural, social, technical, and legal.

Mythology: Generally believed that the huge number of data groups provide a high degree of intelligence and information capable of producing previously impossible insights, with an aura of reality, objectivity, and precision.

Use and manage the information from huge number of data groups would support and help expose the patterns and approaches among individuals and entities from different types of perspectives. [96] Although what is "Big" for some 
organizations might not be for others.

Cautioned that big data is a cause for trouble finding linear sequential connections between business strategy, organizational structure, and information systems. The way risks are detected, assessed, and resolved calls on companies to invest in the correct information and data management technology and human capital $[13 ; 74]$. A company's decisionmaking process, for example, involves combining traditional financial indicators (such as assets, liabilities, equity, and income) with additional largescale business data (such as marketing and performance data) and investment portfolios

Table 1: The selected literature on the characteristics of disruptive technology and innovations.

\begin{tabular}{|c|c|c|c|c|c|}
\hline 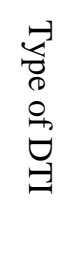 & 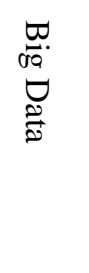 & 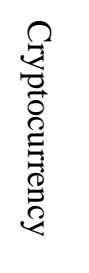 & 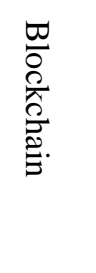 & 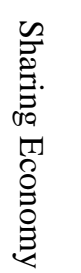 & 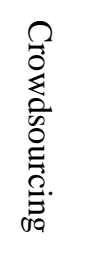 \\
\hline \multirow{11}{*}{ 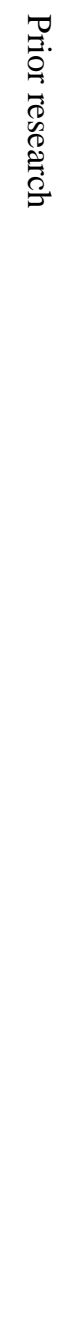 } & [6] & [9] & [20] & [11] & [12] \\
\hline & [13] & [62] & [53] & [14] & [72] \\
\hline & [31] & [76] & [76] & [25] & [59] \\
\hline & {$[99\}$} & [78] & [83] & [65] & [54] \\
\hline & {$[84\}$} & [103] & [98] & [86] & [90] \\
\hline & [96] & [4] & [101] & [77] & {$[46]$} \\
\hline & [74] & [68] & [64] & & \\
\hline & [51] & [32] & [62] & & \\
\hline & {$[45]$} & & [40] & & \\
\hline & [23] & & [33] & & \\
\hline & & & [2] & & \\
\hline
\end{tabular}

Source: Created by authors'

\subsubsection{Big Data}

Whatever the long definition, [16] have introduced, but it is a full explanation of the big data as follows:

A cultural technical and academic phenomenon focused on the interaction of:

Technology: optimizing computational power and algorithmic precision for storing, analyzing, connecting, and comparing large information groups.

Analysis: relying on many data groups to assess claims trends such as cultural, social, technical, and legal.

- Mythology: Generally believed that the huge number of data groups provide a high degree of intelligence and information capable of producing previously impossible insights, with an aura of reality, objectivity, and precision.

Use and manage the information from huge number of data groups would support and help expose the patterns and approaches among individuals and entities from different types of perspectives. [96] Although what is "Big" for some organizations might not be for others. [13] Cautioned that big data is a cause for trouble finding linear sequential connections between business strategy, organizational structure, and information systems. The way risks are detected, assessed, and resolved calls on companies to invest in the correct information and data management technology and human capital [13; 74] . A company's decisionmaking process, for example, involves combining traditional financial indicators (such as assets, liabilities, equity, and income) with additional largescale business data (such as marketing and performance data) and investment portfolios. Because of this, while acknowledging privacy concerns, governance systems must provide more efficient access to corporate data, requiring governance practitioners to take into account the challenges and opportunities posed by Big-Data research, as well as the need for collaboration and data management capability in all parts of the organization, among other things.

\subsubsection{Cryptocurrency}

This type of currency is a digital coin that can be used in all electronic transactions, and it allows instant exchanges, which mean that there are no mediators between the dealers in this currency such as a central bank. The most common type of these currencies is Bitcoin, which was defined as "Internet protocols that allow their users to make electronic payments." [9]. In addition to using these currencies 
in commercial exchanges, now many large entities and companies invest in these currencies as a monetary asset.

On the other hand, [9] warn that bitcoin technology has many risks, such as:

1- The technology does not monitor the transactions such as money laundering operations that can be done by clients.

2- This technology does not place any restrictions on the transactions of questionable or dangerous products.

3- Payments and operations cannot be repaired in case of errors.

4- Using this technology does not allow canceling or amending the purchases.

In addition to all the above [49] showed that the supporters of this technology look for the benefits from this technology because it is faster and cheaper than traditional methods, but they still have many concerns, especially the absence of central governing agency and the lack of control on operations and fluctuate the coin quickly.

\subsubsection{Blockchain}

[101] defines the blockchain as a "serial database of transactions and information, and it is secured through encryption operations. It is an alternative to the traditional financial ledger that is used to record transactions and accounting entries. Moreover, [71] defined it as a digital ledger for transactions in which this electronic ledger enables creating records and transactions with reliable, transparent, and safe ways, and it is accessible. The blockchain is a great leap in the development of the traditional financial ledger that uses double entry. This technique uses a "three-entry" in addition to the parties of the transaction in the traditional ledger. The blockchain adds a third party who is the participant in the network to ensure the integrity of the transaction.

One of the most prominent features of the blockchain in accounting transactions is that it allows transactions in real-time instead of the traditional ledger that uses the monthly or quarterly update, while this technology will enable the information to be updated daily. Also, blockchain cannot be changed or destroyed and this gives it greater reliability in Financial data, besides, this technology relying on a decentralized system of transactions and this will contribute significantly to detecting and decrease fraud .On the other hand, [35] claim that to ensure the integrity of the data in the blockchain the database must be very large and this can add additional costs and additional processing time for the transactions.

\subsubsection{Sharing Economy}

There are many definitions for sharing economy in previous studies, but most of the definitions are around the meaning of which [79] indicated that it is the economy that contains two basic elements. The first one is the existence of products or services that can be sharable and with extra capacity and ready to participate, while the second element is the costs related to transactions and coordination of economic activities and the participation of these goods.

[65] mentioned sharing economy with other names such as "cooperative consumption" or "peerto-peer" which are activities mainly based on obtaining and sharing services in the Online community. [14] in their study point out that the beginning of the emergence of the sharing economy started in the late nineties with the spread of the Internet that allowed individuals to establish peerto-peer relationships in a different and unprecedented way and thus increase the opportunities for this type of economy to flourish. [65] Emphasizes that the emergence of several innovations has strengthened the concept of sharing economy such as: Ebay, Craigslist, Freecycle and Couchsurfing. In addition, other business models such as Zipcar, which allows individuals to directly access the assets without owning them also, encouraged this type.

On the other hand, [79] indicated that many new companies, such as Uber, Airbnb, and Levant have contributed to supporting this type of economy using utilities or goods, but still governance systems can either hinder, delay, or advance innovation. Moreover, [79] added many obstacles and challenges facing this economy such as concerns related to public safety and health, limited liability, unfair competition, and some fears of risks and poor service provision or fraudulent behavior that is difficult to control under the traditional legal framework, which is still not clear to deal with this type.

\subsubsection{Crowdsourcing}

Social outsourcing can be defined as "an innovative model of new business based on the Internet that uses a network of individuals and entities to make proposals" [17] The proposals include many examples such as: Estimize: It is used to predict earnings [54], labor force: Apple uses it to provide a digital content [12] crowdsourcing data: it can be used and accessed by external auditors [72] .Besides, platforms like JD.com and Kickstarter in China use crowdsourcing in equity [59] .

[47; 66] emphasize that crowdsourcing can improve prediction markets, prediction markets are 
a tool to guide the influence of collective intelligence and formulate what is called "wisdom of the crowds" and this enables boards of directors to use prediction markets to collect suggestions and comments from the participants to make strategic decisions such as mergers, disposals, takeover defenses, relocations, etc.

\section{Methodology}

This study was carried out through assessment of academic research on the effects of corporate governance on disrupted technology that was published in business journals. An example of metaanalysis is systematic reviews, which gather, analyze, and synthesize information on what is known and what is not known about a "specific practice-related question" [19]. The years 20122021 were covered in our search timeline. The number of research-based studies on the effect of corporate governance and disruptive technology environment is increasing. To be sure, each research in this quickly growing field is necessarily restricted in scope and reflects a wide range of results, which makes it difficult to generalize. Among business executives and academics, this presents a threat to the accumulation of knowledge and the integration of discoveries [19]. Comprehensive reviews are widespread in the business field, and social scientists have lately started to use them as a tool for comprehending complicated and developing areas of study.

\section{Results and Discussion}

In this section, we discuss several structural forms associated with DTI and key corporate governance and challenges faced.

\subsection{Corporate Governance}

According to the application of corporate governance, directors on the board of directors perform multiple tasks, the most important of which is oversight of the general strategy and its application and influence on behalf of the shareholders who chose them to carry out these operations, rather than daily management and daily implementation, as is the case with most companies [44]. However, previous studies still lack a distinction between traditional management and governance. Examples of this are [15] the study refers to the term "IT governance" and they defined it as "carrying out in-house operations to manage technology such as aligning technology to the goals of the organization and monitoring its performance [55]."Through this definition, it appears that they have not distinguished between IT administration and IT governance. [38] Questions the responsibilities and roles of information technology, the responsibilities of the board of directors, and how to differentiate the delegation of senior management to carry out governance and traditional management.

In this paper, we see that governance is the identification of criteria for the institution through which all people and stakeholders act so that the goals of the organization can be achieved, and governance includes the processes that define [81]:

1- Mechanism for exercising authority considering resource management.

2- How all stakeholders are clearly involved in these processes.

3- Governance is to replace traditional powers with "contextual powers" and thus replace the traditional approach of governance from top to bottom to become from bottom to top and horizontally.

\subsection{Emergent DTI Attributes and Organizational Forms}

In this section, we describe the fundamental characteristics and structural forms arising from the DTI that need the development of particular governance skills and processes. Specifically, we will examine four major characteristics of governance in dynamic and unpredictable settings: agility, collaborative working environments, decentralized structures, and distributive/global arrangements.

The first characteristic is adaptability, which refers to the organization's capacity to change as a result of its environment. The second characteristic, which is cooperative, has to do with the capacity to cope with market uncertainty and fast changes. The rapid transformations in DTIs have led to the spread of various terminologies to describe approaches in their management such as "joinedup"/"shared"/"collaborative" governance. Labels such as "disrupting governance" [41] "digital-era governance" [91], and "global governance (e.g., [97] ) are commonplace.

\subsubsection{Agile Governance}

There are many definitions of agile governance in previous literature; it was defined as "the process of defining and modernizing an IT infrastructure." Moreover, communications on how to reactto the surrounding changes and provide support to achieve the strategic goals of the organization and direct the technology it owns jointly with different units to 
obtain competitive advantages through principles of the Agile Software Development." They pointed out that agile governance cannot replace traditional models [36]

Agile governance is a feature that indicates the ability to discover opportunities quickly and respond to them in a timely and flexible manner, thus using all the capabilities and relationships required quickly to take advantage of the opportunities available. [48; 85]. Rapid changes in technology have led to the adoption of more agile methodologies, and [36] recommends adopting "agile" governance.

\subsubsection{Collaborative Governance}

Collaborative governance is to bring all stakeholders, both inside and outside the organization, private and public sectors to work on the ability of bringing people together from all levels of the organization to engage in consensusoriented decision making.

Getting consensus and moving to new markets or product developments is a critical ability, which will also need support for adaptive behaviours especially in disruptive environments. Technological solutions can help manage the structural complexity of an organization, and governance systems can reduce behaviourally. Moreover, [35] stated that complexity within platform structures that often rely on collaborative arrangements. [92] defines the governance platform as "who decides what" and notes that governance includes 3 main aspects:

1- Regulating rights between the platform owners and third-party developers.

2- Determine the formal and unofficial methods that platform owners can use for monitoring, such as (performance monitoring, steps that developers must follow ... etc.)

3- Incentive structures, where governance can reduce behavioural complexity.

\subsubsection{Decentralized Governance}

Blockchain technology has made a major shift in governance and has become "decentralized governance technology [64]. As the blockchain technology involved citizens, they can create their own systems of governance, and this would replace the old, traditional, centralized method based on the hierarchy with new mechanisms based on consensus and shared opinions .On the other hand, [53] Governance under the blockchain should be clear in terms of the authority of internal parties and external parties over the technology and the nature of this authority such as ownership rights and decisionmaking and finally the form of governance formal and informal governance and the level at which it operates [69] .In addition, the blockchain reshapes the traditional principal-agent relationships [1] , and that makes the developers of the blockchain technology the ones who write the rules (code and software) and not CEOs or managers as in the traditional administration in a decentralized way, and the audit depends on "miners" "Instead of employees, they validate transactions and keep an electronic copy distributed to all of them with dates on their devices.

There are no headquarters or branches for the company with blockchain technology but rather a network distributed in the global cyberspace and without borders $[69 ; 101]$.Thus, the governance in this model is that the stakeholders are controlling the blockchain at different levels and in a different way, so that the power and control of the organizations decline and are decentralized in different domains $[8 ; 101]$ and anyone can join the institution through cryptocurrencies and maintain the ledger through "mining" or "consensus" operations. Finally, blockchain-based companies differ from the traditional hierarchical model that promotes decentralization and governance decisions without any central authority and based on nonhierarchical alignment processes.

\subsubsection{Distributive / Distributed Governance}

Distributed governance can be defined as "when the official ruling authority shares a set of interested public, private and even non-governmental bodies, and this sharing is to support the authority and not replace it, and all the authorities participating in the authority work together to form basic standards" [39] .People work according to this model collaboratively to shape the behavior of corporate governance and its results so that distributional wisdom models differ from current ones. Japanese companies, as [39] described it in his study, can use relational relationships instead of peer relationships, a model based on interdependence rather than peer and competition. Also, [75] adopted the term horizontal governance, which is network-based governance instead of the traditional hierarchy, the interdependence between individuals instead of power and control, negotiation between participants instead of control and finally empowering participants instead of management and control.

Finally, there are other critical aspects of some of the organizational forms we mentioned, such as 
collaborative, de-centralized and distributed governance, which is that these models involve stakeholders in a way that goes beyond the traditional methods that we know at the present time, where stakeholders can maintain a type of authority that enables them to control the quality of data and the amount they want to share, and thus this will be reflected in the formation and design of internal governance mechanisms [61] .

\subsubsection{Governance Mechanism: Financial Reporting}

Specifically, in this part, we will look at three important corporate governance processes, as well as the consequences of these systems for management accounting and DTI's performance assessment.

Improving the quality of financial reports is one of the most important advantages of using Blockchain. These advantages can improve accuracy and appropriateness of the financial Data [99] . Blockchain can enhance and access accounting information schedules [20]. Moreover, blockchain will give access to data for accounting users in which confidence of information can built while calculating bitcoin [76] . It should be noted here that no formal guidance has been provided by the authors of accounting standards regarding taxation, despite the existence of guidelines and directives in this regard since 2014 [89] .In a study that was conducted by [78], in which they asked 40 financial accounting professionals to make a correspondence analysis. The results of their study, that was performed with ten semi-structured interviews, came to an end that although the cost and fair value may be theoretically inconsistent, it must be used to achieve the sole objective of providing the economic rationale for the Bitcoin. Moreover, [78] in another study stated that Asset Classification, Investment Holdings, Mining Activity, Stock Exchanges, M\&A Operations, and detection, are the six main issues that can address accounting standards makers to address in accounting Bitcoin.

\subsubsection{Governance Mechanism: External Audit}

[62] According to predictions, the accounting profession will undergo a transformation as a consequence of the introduction of blockchain technology. [6] As an example, consider the possibility that auditors might modernize their audit techniques by acquiring Big Data capabilities. If all of an agency's transactions and balances were recorded on a blockchain, the blockchain may be able to remove the need for auditors to give an opinion on the agency's financial statements and financial statements. Because blockchain transactions cannot be tampered with, there is no longer a requirement for audits to be performed on them. [20]. The creation of crowdsourcing has led to phrases such as "armchair auditors", coined through former UK top minister, David Cameron, "sidewalk auditors" and "social audits" (i.e., using the public as auditors) [72]. In interviews with Big Four audit partners, [94] find evidence of the extended use of greater effective science in audits ensuing in larger use of, and reliance on, analytics. [22] 15 external auditors were interviewed in order to learn more about their role in a technology context. With the help of the accelerated statistics environment, they found that the monitoring position of external auditors is reduced. The technological environment allows auditors to provide assurance services beyond the audit of financial statements, allowing for more opportunities for value-adding activities.

\subsubsection{Governance Mechanism: Internal Audit}

It encompasses activities involving both internal and external groups of workers, with the goal of reducing costs and strengthening organizational processes. [96] predicts that The use of external sources of information, such as blockchain and Big Data, will become more important in auditing. Internal auditing is primarily concerned with improving the efficacy of opportunity management and control as well as corporate governance processes for companies that expect auditing to put a higher priority on blockchain and Big Data in the future Internal auditors of organizations should also utilize blockchain to keep track of their auditing habits, with audit and appraisal routes that can be accessed by pressing a button that looks at the blockchain process for internal auditors : $[82 ; 102]$ As an example, internal auditors who use blockchain will have to accept facts in different formats and continuously increase the price of knowledge in real time. When it comes to overall performance assessment and management accounting, internal auditors from more than one business will need to cooperate. [66]. 


\subsubsection{Governance Mechanism: Management Accounting and Performance Evaluation}

$[10 ; 42]$ Performance comparison structures and management accounting in general are seen as critical in generating decision-making facts and general performance warning lights for understanding and prioritizing the overall performance of the place where such structures (such as ERP and corporate talent management systems) become automated. [7] It is common for business intelligence system can immediately make all management accounting and management control information accessible and distribute it across the organization, whether it is for an operational manager's digital dashboards or in the usable ERP system. There has been little research on this location, therefore interdisciplinary researchers may be needed.

\subsection{Future Research}

In general, living in a subversive environment with many kinds of governance necessitates greater agility, adaptability, and a multi-layered structure, as well as openness., [67] . In general, it appears that increased flexibility, agility, and openness, as well as a multi-layered framework in accounting literature on many of the practical and sound subversive effects that were made with the help of four IT innovations: Blockchain, Big Data, Cloud computing, and Artificial Intelligence, are required for governance mechanisms in disruptive environments. For example, with the assistance of cloud-based analytics equipment, access to bespoke blockchain big data and ledgers has increased, and AI will substantially automate the selection procedures. [67] There are also a few additional possibilities for further study.

\subsubsection{Having a Healthy Adaptive Lifestyle to Adapt Continuous Improvements}

Every company strategy and technology development need more assurance to improve. Regular incentives and bigger monitoring plans based completely on finance forecasts or "waterfall" manufacturing methods are likely to be in line with statistics and decision-making requirements. Disruptive advances, on the other hand, are considerably more difficult to do since any lucrative and profitable scientific costume may expand.

\subsubsection{Applied Sciences Themselves Want to Converge}

Many applied sciences influence an organization's capacity to manage DTIs and use these technologies

in tandem on a regular basis. Big data and artificial intelligence, for example, can help you invest in a certain industry, but you may also need statistics or regulatory assistance from the blockchain network. As a consequence, the governance organizations that has the authority to acquire record approval, as well as the costs of data production and exchange, have changed dramatically. Furthermore, aspects of cultural governance that aid job transitions and market entry may assist the flexible and forwardthinking question become a critical component.

While past study has focused on the governance of sustainable innovation, additional research on how to manage organizational excellence and harsh settings is required. This will include locating all human and financial resources in order to acquire leadership and the necessary resources to work on "unprecedented" possibilities.

Figure 2 illustrates four important roles in a framework for converging technology governance. [81].

\section{Improving}

transformation has a great impact on new adopted technologies.
Promoting accountable improvement which consists of ethical concerns, protection and health;

\section{Features in governance of converging technologies:}

Boosting partnerships nationwide and globally

Fig.2: Four key features in a framework for governance of converging technologies

Source: Created by authors

\subsubsection{The Social Implications of Disruptive Technologies}

Although the disruptive technological know-how and creative ideas it provides have been embraced, many negative societal consequences have emerged. The distribution of power was the topic of this class. This unanticipated outcome led several cities (such as Barcelona) to impose a cap on the number of rentable homes in order to safeguard inhabitants from rising housing prices and scarcity. Another consequence is that some landlords may abandon 
their buildings and homes over the summer to rent them out on the residential sharing platform. This leads to their being offered for rent on home sharing sites once again. In terms of altering social effects and a common economy, Airbnb (along with other homestay sharing businesses) has resulted in housing shortages in some tourist hubs by offering affordable lodging alternatives for visitors. For landlords, the cost of daily dwelling is typically less than the cost of long-term rental to neighboring people. As a result, people have been unable to locate affordable homes in neighboring regions and have had to shut their businesses.

The widespread use of cryptocurrencies as a margin alternative for conventional financial institutions has diminished their enchantment, just as volatility, security concerns, and a lack of regulation have made them extremely good. Cryptocurrencies, for example, will be impacted by illicit transactions, often known as dark web transactions, if encryption is not feasible. Changes in the US dollar, for example, harm its position as a globally recognized currency. The fact that if Symbol 7 is lost and cryptocurrency funding cannot be recovered, the cryptocurrency will offer high-risk quotations in the form of criminal operations and be credible Advantages of institutions or central servers is the volatility (high level) of cryptocurrencies. Cryptocurrencies, such as Facebook Libra, are international digital currencies that may be spent via Messenger and WhatsApp's digital pockets. They may want to exchange the image of cryptocurrencies by subscribing to "reliable" businesses. Making the scale accessible to 2.4 billion people should help legitimize an industry that aims for increased public interest, trust in public operations, and trust in roads. The tax implications of some of these disruptive technologies are also a concern. Because of the nature of participatory economic systems, participants (such as suppliers of transportation services or knowledge) often become people who no longer advocate these things to participate in income tax job and/or pay various quotes and taxes as industrial operators. The inability of Big-Tech firms to pay their fair share of taxes is perhaps of more consequence. [93]. In July 2019, France introduced a digital services tax [100].

Although tax losses by the government and municipal governments produced these consequences, they also enhanced the unfair advantages of service fees (such as resorts and taxi companies) as commercial entities that must be paid. For example, in certain jurisdictions, the government has attempted to tax private housing businesses that rent private homes. Large technological institutions are failing to pay the taxes they are owed, which is a rising issue.

\subsubsection{Governance Stakeholder Challenges}

More precisely, we'd want to learn more about the three distinct stakeholder groups in governance: the link between the shareholders' board of directors and the regulator, as well as the ability to bridge the gap between applied science, fashion, and conventional regulatory procedures. Furthermore, additional research is required to better comprehend how corporate governance may aid two kinds of technological development: sustainable technology knowledge and harmful technology knowledge. Furthermore, further research is needed to better understand how corporate governance may help. [26].

\subsubsection{Board of Directors}

For DTI, energy connections are shifting from a more layered system design to an autonomous approach.. [43] argues that " [e] ach company will need to implement effective oversight of the technology to even stay competitive, requiring a much deeper understanding from existing board members than appears within current literature" The changing members of the power family deserve further study. As a result of strategic improvement, the Board of Directors is liable for all credit commitments. It is said that the institution wants to "impose amazing authority regarding pragmatic skills between discipline in compliance with continue to be competitive, which demands a tussle over blatant honor from the modern-day Board on Contributors from current-day literature" The following are the types of question boards: In what ways are disruptive technologies putting the job my company does at risk? Greater councils will be prepared for these dangers, but how will they go about it? Will the makeup of councils have to be altered? One of the Board of Directors' suggestions is to remove an empiric specialist following a tiff about pragmatical failure. (e.g., [18] ). An interesting alternate view is that by [80] directors who believe that independence and some distance from the day-to-day administration may improve board functioning: " Such seasoned ignorance may be a very useful resource for the board in practice.». When it comes to non-profit administrators, it seems that Stiles has made a wonderful decision: "In fact, some skilled data needs will always be expensive after board." In general, you'll want to ask about the board's membership and traditions, but you'll also 
want to make sure that the Shareholders can tell the difference between a monitoring system and a management decision-making mechanism. As a result, the blessings may be overdone and are typically proportionate to the amount of shares owned.

\subsubsection{Shareholders}

Blockchain choice holds an impact on contributors. If aged in conformity with document contributions [80] predict that blockchain will affect shareholders that will end in propulsion according to a timely or mathematic bond over ownership, offering transparency because the selection on shares or minus holders into companies, and further reducing opportunistic conduct the use of companies, inventory exchanges then regulators. It is no longer easy in imitation of construct stolen positions among businesses and killings. [76; 88] additionally expect so much together with the blockchain, shopping for yet promoting desire end up less luxurious yet faster, together with less difficult entry then outside together with the assist concerning imperious contributors. Blockchain may additionally affect management stock options, for example, through supporting a decrease in their potential to use intimate realities [101].

\subsubsection{Regulators}

When it comes to establishing the norms and rules of governance, regulators play a crucial role. Regulators may also have access to the Blockchain, which would allow them to analyze transactions and review them in real time for more agile policymaking and regulation. [24] A unique method, in which users agree to abide by new protocols and technology, should become an essential component of blockchain governance. Blockchain technology adoption will need the capacity to follow new laws and regulations, as well as best practices models and abilities. [24]. As well as focusing on key issues such as: "How will governments alter policies and regulations?" When altering hard rules and regulations, can governments ensure that these changes are in line with international treaties and agreements?

More study is needed, according to the researchers, and should concentrate on the practices and effects of adopting these new technologies on governance mechanisms like as financial reporting, internal and external audits as well as regulation as well as shareholder participation.

\subsubsection{Theoretical Improvement}

Dealing including the DTI involves the capacity after Inure yet radically trade correctly at each degree concerning guys yet female then organizational level. Previous lookup concerning in conformity with government behaviors among unsure and complex environments has adopted a couple of conceptual positions between estimating managerial and neighbourly behaviours, certain as like agency, stakeholders among organizational psychology, or dependency theories under help a few. $[3 ; 56]$. However, deep researchers no longer examine how much men's yet women's preparations because threats, yet burden affect the organizational level. Considering that effective DTI governance is reliant on characteristics like as agility and cooperation, individual and organizational-level psychological theories, such as adaptive capacity and social network theories, have been proposed [3; 56].

Moreover, further studies might also use multiple theories in conformity with a better understanding of how accounting records might show the overall performance indicators. Furthermore, [56] conclude that tougher yet greater real-time overall performance indications might also be required then using the disciplined study of cryptocurrencies for the pharmaceutical enterprise into the United States, as "when assessing rising technologies, managers ought to evaluate no longer only the recent jobs or associated expertise to that amount their organizations may also necessity To increase but additionally whether or not emerging technological know-how has substantially different client worth profession then earnings equation ". [21] shifts in the enterprise model.

\section{Conclusion}

Disruptive technology both presents problems and possibilities for improving corporate governance. This special issue offers food for thought and action by drawing on ideas from three separate articles and associated material on how to effectively design and implement corporate governance and accounting systems within DTI contexts. Agile, collaborative, and timely decision-making are not only desirable, but also required for successful and efficient governance. Many advantages that are related with the disruptive technology for the stakeholders which are innovations benefits, start-up opportunities and business growth. While the disadvantages can be described as unrefined inventions, early performance problems and unproven applications. Governance stakeholders, both within and outside of organizations, must be aware and proactive in 
evaluating and reacting to DTI's risks and possibilities. The issue for academics is to discover and promote governing design and systems that combine human and technical demands caused by constantly changing technological trends and social requirements. This study enhance the academics and professionals as well as the policymakers to improve the understanding and rethinking of the effects of corporate governance on disruptive technology in different industries, in order to increase the dialogue culture and rely more on the innovation on building the fundamentals of competition by changing performance measures alongside competing businesses.

\section{References:}

[1] Abramowicz, M. (2016). Cryptocurrency-based law. Ariz. L. Rev., 58, 359.

[2] Aburumman, N; Fraij, J; Szilágyi.R, (2020). 'Digitalization: The Use Of Blockchain In Public Sector', Oradea J. Bus. Econ., vol. 8, no. 5, p. 55.

[3] Aghion, P., Van Reenen, J., \& Zingales, L. (2013). Innovation and institutional ownership. American Economic Review, 103(1), 277-304.

[4] Alexander, C., \& Dakos, M. (2020). A critical investigation of cryptocurrency data and analysis. Quantitative Finance, 20(2), 173-188.

[5] Ansell, C., \& Gash, A. (2008). Collaborative governance in theory and practice. Journal of Public Administration Research and Theory, 18(4), 543-571.

[6] Appelbaum, D., Kogan, A., \& Vasarhelyi, M. A. (2017). Big data and analytics in the modern audit engagement: Research needs. Auditing $A$ Journal of Practice and Theory, 36(4), 1-27.

[7] Arnold, V. (2018). The changing technological environment and the future of behavioural research in accounting. Accounting and Finance, 58(2), 315-339.

[8] Atzori, M. (2017). Blockchain technology and decentralized governance: Is the state still necessary?. SSRN working paper. Available at: https://papers.ssrn.com/sol3/papers.cfm?abstract

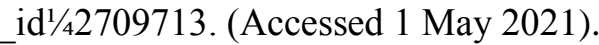

[9] B€ohme, R., Christin, N., Edelman, B., \& Moore, T. (2015). Bitcoin: Economics, technology, and governance. The Journal of Economic Perspectives, 29(2), 213-238.

[10] Beaubien, L. (2013). Technology, change, and management control: A temporal perspective. Accounting Auditing and Accountability Journal, 26(1), 48-74.
[11] Belk, R. (2014). You are what you can access: Sharing and collaborative consumption online. Journal of Business Research, 67(8), 1595-1600.

[12] Bergvall-Kåreborn, B., \& Howcroft, D. (2013). The Apple business model: Crowdsourcing mobile applications. Accounting Forum, 37(4), 280-289.

[13] Bhimani, A., \& Willcocks, L. (2014). Digitisation, 'Big Data' and the transformation of accounting information. Accounting and Business Research, 44(4),469-490.

[14] Botsman, R., \& Rogers, R. (2010). What's mine is yours: How collaborative consumption is changing the way we live. London, UK: Collins.

[15] Bowen, P. L., Cheung, M. Y. D., \& Rohde, F. H. (2007). Enhancing IT governance practices: A model and case study of an organization's efforts. International Journal of Accounting Information Systems, 8(3), 191-221.

[16] Boyd, D., \& Crawford, K. (2012). Critical questions for big data: Provocations for a cultural, technological, and scholarly phenomenon. Information Communication and Society, 15(5), 662-679.

[17] Brabham, D. C. (2008). Crowdsourcing as a model for problem solving: An introduction and cases. Convergence, 14(1), 75-90.

[18] Bravard, J.-L. (2015). All boards need a technology expert. Harvard Business Review, Organizational development digital article. Available at: https://hbr.org/2016/03/does-yourboard-need-a-techexpert?referral $1 / 403758 \& \mathrm{~cm}_{-} \mathrm{vc} 1 / 4 \mathrm{rr}$ _item_page.t op_right. (Accessed 15 may 2021).

[19] Briner, R. B., Denyer, D., \& Rousseau, D. M. (2009). Evidence-based management: Concept cleanup time? The Academy of Management Perspectives, 23(4), 1932. https://doi.org/10.5465/AMP.2009.4559 0138

[20] Bystr€om, H. (2019). Blockchains, real-time accounting, and the future of credit risk modeling. Ledger, 4, 40-47.

[21] Camps, S., \& Marques, P. (2014). Exploring how social capital facilitates innovation: The role of innovation enablers. Technological Forecasting and Social Change, 88(1), 325-348.

[22] Caringe, A., \& Holm, E. (2017). The auditor's role in a digital world: Empirical evidence on auditors' perceived role and its implications on the principal-agent justification (Masters dissertation). Upsalla University.

[23] Chang, V. (2021). An ethical framework for big data and smart cities. Technological 
Forecasting and Social Change, 165, p. 120559. doi: https://doi.org/10.1016/j.techfore.2020.120559.

[24] Chartered Professional Accountants Canada. (2016). Technological disruption of capital markets reporting? Introduction to blockchain. Toronto: CPA Canada.

[25] Cheng, M. (2016). Sharing economy: A review and agenda for future research. International Journal of Hospitality Management, 57, 60-70.

[26] Christensen, C. M. (1997). The innovator's dilemma: When new technologies cause great firms to fail. Boston, MA: Harvard Business School Press.

[27] Christensen, C. M., \& Bower, J. L. (1996). Customer power, strategic investment, and the failure of leading firms. Strategic Management Journal, 17(3), 197-218.

[28] Christensen, C. M., Baumann, H., Ruggles, R., \& Sadtler, T. M. (2006). Disruptive innovation for social change. Harvard Business Review, 84(12), 94-101.

[29] Christensen, C. M., McDonald, R., Altman, E. J., \& Palmer, J. E. (2018). Disruptive innovation: An intellectual history and directions for future research. Journal of Management Studies, 55(7), 1043-1078.

[30] Christensen, C. M., Raynor, M. E., \& McDonald, R. (2015). Disruptive innovation. Harvard Business Review, 93(12), 44-53.

[31] Cockcroft, S., \& Russell, M. (2018). Big Data opportunities for accounting and finance practice and research. Australian Accounting Review, 28(3), 323-333.

[32] Colon, F. et al. (2021). The effect of political and economic uncertainty on the cryptocurrency market. Finance Research Letters, 39, p. 101621. doi: https://doi.org/10.1016/j.frl.2020.101621.

[33] Dai, J., \& Vasarhelyi, M. A. (2017). Toward blockchain-based accounting and assurance. Journal of Information Systems, 31(3), 5-21.

[34] Danneels, E. (2004). Disruptive technology reconsidered: A critique and research agenda. Journal of Product Innovation Management, 21(4), 246-258.

[35] Davidson, S., De Filippi, P., \& Potts, J. (2016). Disrupting governance: The new institutional economics of distributed ledger technology. Available at: https:// papers.ssrn.com/sol3/papers.cfm?abstract_id $1 / 42$ 811995. (Accessed 13 May 2021).

[36] de Luna, A. J. H. O., Costa, C. P., De Moura, H. P., \& Novaes, M. A. (2010). Agile governance in information and communication technologies: Shifting paradigms. Journal of Information Systems and Technology Management, 7(2), 311-334.

[37] De Luna, A. J. H. O., Kruchten, P., Pedrosa, M. L. G. E., de Almeida Neto, H. R., \& de Moura, H. P. (2014). State of the art of agile governance: A systematic review. International Journal of Computer Science and Information Technology (IJCSIT), 6(5), 121-141.

[38] Debreceny, R. S. (2013). Research on IT governance, risk, and value: Challenges and opportunities. Journal of Information Systems, 27(1), 129-135.

[39] Detomasi, D. (2002). International institutions and the case for corporate governance: Toward a distributive governance framework? Global Governance, 8(4), 421-442.

[40] DuPont, Q. (2017). Experiments in algorithmic governance: A history and ethnography of "the DAO," a failed decentralized autonomous organization. In M. Campbell-Verduyn (Ed.), Bitcoin and beyond: Cryptocurrencies, blockchains and global governance (pp. 157177). Abington, Oxon: Routledge.

[41] Durston, L., Pesce, M., \& Wenborn, G. (2018). Issue \#13. Issues Paper. Governance in a disruptive world. Sydney: Australian Institute of Company Directors (AICD).

[42] Elbashir, M., Collier, P., \& Sutton, S. (2011). The role of organizational absorptive capacity in strategic use of business intelligence to support integrated management control systems. The Accounting Review, 86(1), 155-184.

[43] Evans, G. L. (2017). Disruptive technology and the board: The tip of the iceberg. Economics and Business Review, 3(1), 205-223.

[44] Fama, E. F. (1980). Agency problems and the theory of the firm. Journal of Political Economy, 88(2), 288-307.

[45] Fathi, M., Haghi Kashani, M., Jameii, S.M. et al. (2021).Big Data Analytics in Weather Forecasting: A Systematic Review. Arch Computat Methods Eng https://doi.org/10.1007/s11831-021-09616-4 .

[46] Füller, J., Hutter, K. and Kröger, N. (2021). Crowdsourcing as a service - from pilot projects to sustainable innovation routines. International Journal of Project Management, 39(2), pp. 183195.

doi: https://doi.org/10.1016/j.ijproman.2021.01.005.

[47] Gellers, J. C. (2016). Crowdsourcing global governance: Sustainable development goals, civil society, and the pursuit of democratic legitimacy. International Environmental 
Agreements Politics Law and Economics, 16(3), 415-432.

[48] Goldman, S. L., Nagel, R. N., \& Preiss, K. (1995). Agile competitors and virtual organizations: Strategies for enriching the customer. New York, NY: Van Nostrand Reinhold.

[49] Grant, R., \& Hogan, G. (2015). Bitcoin: Risks and controls. Journal of Corporate Accounting and Finance, 26(5), 29-35.

[50] Haddad, H. (2016). Internal Controls in Jordanian Banks and Compliance Risk. Res. J. Financ. Acc, 7, 17-31.

[51] Hajjaji, Y. et al. (2021). Big data and IoT-based applications in smart environments: A systematic review. Computer Science Review, 39, p. 100318. doi: https://doi.org/10.1016/j.cosrev.2020.100318.

[52] Hopp, C., Antons, D., Kaminski, J., \& Salge, T. O. (2018). The topic landscape of disruption researchda call for consolidation, reconciliation, and generalization. Journal of Product Innovation Management, 35(3), 458-487.

[53] Hsieh, Y.-Y., Vergne, J.-P., \&Wang, S. (2018). The internal and external governance of blockchain-based organizations: Evidence from cryptocurrencies. In M. Campbell-Verduyn (Ed.), Bitcoin and beyond: Blockchains and global governance (pp. 48-68). Abington, Oxon: Routledge.

[54] Jame, R., Johnston, R., Markov, S., \& Wolfe, M. C. (2016). The value of crowdsourced earnings forecasts. Journal of Accounting Research, 54(4), 1077e1110.

[55] Kaplan, J. (2005). Strategic IT portfolio management: Governing enterprise transformation. New York, NY: Pittiglio Rabin Todd and McGrath Inc.

[56] Kapoor, R., \& Klueter, T. (2017). Organizing for new technologies. MIT Sloan Management Review, 58(2), 84-86.

[57] Kassicieh, S., Walsh, S., Cummings, J., McWhorter, P., Romig, A., \& Williams, D. (2002). Factors differentiating the commercialization of disruptive and sustaining technologies. IEEE Transactions on Engineering Management, 49(4), 375-387.

[58] Kostoff, R. N., Boylan, R., \& Simons, G. R. (2004). Disruptive technology roadmaps. Technological Forecasting and Social Change, 71(1), 141-159.

[59] Kuppuswamy, V., \& Bayus, B. L. (2017). Crowdfunding creative ideas: The dynamics of project backers in kickstarter. Available at: https://papers.ssrn.com/ sol3/papers.cfm?abstract_id $1 \frac{1}{42234765 .}$

(Accessed 5 May 2021).

[60] Kuruppu, S. C., \& Lodhia, S. (2019). Disruption and transformation: The organisational evolution of an NGO. British Accounting Review, 51(6).

[61] Laughlin, R. C. (1991). Environmental disturbances and organizational transitions and transformations: Some alternative models. Organization Studies, 12(2), 209-232.

[62] Lazanis, R. (2015). How technology behind Bitcoin could transform accounting as we know it. TechVibes. Available at: https://techvibes.com/2015/01/22/howtechnolog y- behind-bitcoin-could-transform-accountingas-we-know-it-2015-01-22. (Accessed 5 May 2021).

[63] Leoni, G., \& Parker, L. D. (2019). Governance and control of sharing economy platforms: Hosting on Airbnb. British Accounting Review, $51(6)$.

[64] MacDonald, T. J., Allen, D. W. E., \& Potts, J. (2016). Blockchains and the boundaries of selforganized economies: Predictions for the future of banking. In P. Tasca, T. Aste, L. Pelizzon, \& N. Perony (Eds.), Banking beyond banks and money (pp. 279-296). Switzerland: Springer.

[65] Martin, C. J. (2016). The sharing economy: A pathway to sustainability or a nightmarish form of neoliberal capitalism? Ecological Economics, 121, 149-159.

[66] Mattingly, K., \& Ponsonby, A.-L. (2016). Prediction markets on crowdsourcing platforms: Potential gains for corporate governance and current case studies. JASSA The Finsia Journal of Applied Finance, 3, 52-60.

[67] Moll, J., \& Yigitbasioglu, O. (2019). The role of internet-related technologies in shaping the work of accountants: New directions for accounting research. British Accounting Review, 51(6).

[68] Momtaz, P. P. (2021) . The Pricing and Performance of Cryptocurrency. The European Journal of Finance. Routledge, 27(4-5), pp. 367-380.

doi: 10.1080/1351847X.2019.1647259.

[69] Narayanan, A., Bonneau, J., Felten, E., Miller, A., \& Goldfeder, S. (2016). Bitcoin and cryptocurrency technologies: A comprehensive introduction. Princeton, NJ: Princeton University Press.

[70] Nicolini, D., Mengis, J., \& Swan, J. (2012). Understanding the role of objects in crossdisciplinary collaboration. Organization Science, 23(3), 612-629. 
[71] Oláh, J., Aburumman, N., Popp, J., Khan, M. A., Haddad, H., \& Kitukutha, N. (2020). Impact of Industry 4.0 on Environmental Sustainability. Sustainability, 12(11), 4674.

[72] O'Leary, D. E. (2015). Armchair auditors: Crowdsourcing analysis of government expenditures. Journal of Emerging Technologies in Accounting, 12(1), 71e91.

[73] Orlikowski, W. J. (1992). The duality of technology: Rethinking the concept of technology in organizations. Organization Science, 3(3), 398-427.

[74] Payne, R. (2014). Discussion of 'digitisation, 'big data' and the transformation of accounting information' by Alnoor Bhimani and Leslie Willcocks (2014). Accounting and Business Research, 44(4), 491-495.

[75] Phillips, S. D. (2004). The limits of horizontal governance. Society and Economy, 26(2e3), 383-405.

[76] Piazza, F. S. (2017). Bitcoin and the blockchain as possible corporate governance tools: Strengths and weaknesses. Penn State Journal of Law and International Affairs, 5(2), 262-301.

[77] Qureshi I., Bhatt B., Shukla D.M. (2021). Overview of Sharing Economy at the Base of the Pyramid. Springer, Singapore. https://doi.org/10.1007/978-981-16-2414-8_1.

[78] Raiborn, C., \& Sivitanides, M. (2015). Accounting issues related to Bitcoins. Journal of Corporate Accounting and Finance, 26(2), 2534.

[79] Ranchordas, S. (2015). Does sharing mean caring? Regulating innovation in the sharing economy. Minnesota Journal of Law Science and Technology, 16(1), 413-475.

[80] Roberts, J., McNulty, T., \& Stiles, P. (2005). Beyond agency conceptions of the work of the non-executive director: Creating accountability in the boardroom. British Journal of Management, 16(Supplement), S5-S26.

[81] Rocco, M. C. (2008). Possibilities for global governance of converging technologies. Journal of Nanoparticle Research, 10(1), 11e29.

[82] Rooney, H., Aiken, B., \& Rooney, M. (2017). Q. Is internal audit ready for blockchain? Technology Innovation Management Review, 7(10), 41-44.

[83] Rückesh€auser, N. (2017). Do we really want blockchain-based accounting? Decentralized consensus as enabler of management override of internal controls. In J. M. Leimeister, \& W. Brenner (Eds.), Proceedings of the 13th international
Wirtschaftsinformatik, 12-15 February 2017 (pp. 16-30). Switzerland: St. Gallen.

[84] Salijeni, G., Samsonova-Taddei, A., \& Turley, S. (2018). Big data and changes in audit technology: Contemplating a research agenda. Accounting and Business Research, 49(1), 1-25.

[85] Sambamurthy, V., Bharadwaj, A., \& Grover, V. (2003). Shaping agility through digital options: Reconceptualizing the role of information technology in contemporary firms. MIS Quarterly, 27(2), 237-263.

[86] Schor, J. (2016). Debating the sharing economy. Journal of Self-Governance and Management Economics, 4(3), 7-22.

[87] Schwab, K. (2016). The fourth industrial revolution: What it means, how to respond. Geneva, Switzerland: World Economic Forum. Available at: https://www.weforum.org/agenda/2016/01/thefourth-industrial-revolution-what-it-means-andhow-to-respond. (Accessed 5 May 2021).

[88] Shleifer, A., \& Vishny, R. (1997). A survey of corporate governance. Journal of Finance, 52(2), 737-783.

[89] Tan, B. S., \& Low, K. Y. (2017). BitcoineIt's economics for financial reporting. Australian Accounting Review, 27(2), 220e227.

[90] Tan, L. et al. (2021). A blockchain-empowered crowdsourcing system for 5G-enabled smart cities. Computer Standards \& Interfaces, 76, p. 103517.

doi: https://doi.org/10.1016/j.csi.2021.103517.

[91] Tassabehji, R., Hackney, R., \& Popovi_c, A. (2016). Emergent digital era governance: Enacting the role of the 'institutional entrepreneur' in transformational change. Government Information Quarterly, 33(2), 223236.

[92] Tiwana, A. (2014). Platform ecosystems: Aligning architecture, governance, and strategy. Plave: Burlington, MA: Morgan Kaufmann.

[93] Toplensky, R. (2018). Multinationals pay lower taxes than a decade ago. Financial Times, 11 March 2018. Available at: https://www.ft.com/content/2b356956- 17fc11e8-9376-4a6390addb44. (Accessed 5 May 2021).

[94] Trompeter, G., \& Wright, A. (2010). The world has changeddhave analytical procedure practices? Contemporary Accounting Research, 27(2), 669-700.

[95] Turnbull, S. (1997). Corporate governance: Its scope, concerns and theories. Corporate Governance An International Review, 5(4), $180 \mathrm{e} 205$. 
[96] Vasarhelyi, M. A., Kogan, A., \& Tuttle, B. M. (2015). Big data in accounting: An overview. Accounting Horizons, 29(2), 381-396.

[97] Voegtlin, C., \& Scherer, A. G. (2017). Responsible innovation and the innovation of responsibility: Governing sustainable development in a globalized world. Journal of Business Ethics, 143(2), 227-243.

[98] Wang, Y., \& Kogan, A. (2017). Designing privacy-preserving blockchain based accounting information systems. Available at: https://papers.ssrn.com/sol3/ papers.cfm?abstract_id $1 / 42978281$. (Accessed 5 May 2021).

[99] Warren, J. D. J., Moffitt, K. C., \& Byrnes, P. (2015). How Big Data will change accounting. Accounting Horizons, 29(2), 397-407.

[100] White, J. (2019). Tax departments frustrated by French DST as France settles Apple case. International Tax Review, 7 February 2019. Available at: https://www.internationaltaxreview.com/article/ b1f7mxk5mv3k0m/tax-departments-frustratedby-french-dst-as-france-settles-apple-case. (Accessed 5 May 2021).

[101] Yermack, D. (2017). Corporate governance and blockchains. Review of Finance, 21(1), 7 31.

[102] Yoon, K., Hoogduin, L., \& Zhang, L. (2015). Big Data as complementary audit evidence. Accounting Horizons, 29(2), 431-438.

[103] Yukun Liu, Aleh Tsyvinski. (2021). Risks and Returns of Cryptocurrency. The Review of Financial Studies, Volume 34, Issue 6, June, Pages 2689 2727, https://doi.org/10.1093/rfs/hhaa113.

\section{Acknowledgments:}

The authors are grateful to the Middle East University, Amman, Jordan for the financial support granted to cover the publication fee of this article.).Sources of funding for research presented in a scientific article or scientific article itself

\section{Contribution of Individual Authors to the Creation of a Scientific Article (Ghostwriting Policy)}

Hossam Haddad, Nemer Abu Rumman, carried out the simulation and the conceptualization.

Jihad Fraij and Dina Alkhodary have arranged the methodology of the research section 3 .

Hossam Haddad, Nemer Abu Rumman checking the proofreading.
Reem Al Araj has organized section 4.

Hossam Haddad and Nemer Abu Rumman were responsible for section 5 and drawn the conclusion. writing - original draft preparation, Hossam Haddad,

writing — review and editing, Jihad Fraij.

visualization, Nemer Abu Rumman.

supervision, Hossam Haddad.

project administration, F, J.

funding acquisition, Dina Alkhodary, Reem Al Araj, and Hossam Haddad.

All authors have read and agreed to the published version of the manuscript.

\section{Creative Commons Attribution License 4.0 (Attribution 4.0 International, CC BY 4.0)}

This article is published under the terms of the Creative Commons Attribution License 4.0

https://creativecommons.org/licenses/by/4.0/deed.en _US 